\title{
Resumo
}

\section{On the use of ethanol for evaluating microporosity of activated carbons prepared from Polish lignite}

\author{
Microporous activated carbons prepared by $\mathrm{KOH}$ chemical activation or steam \\ activation from lignite were characterised by adsorption of $\mathrm{N} 2$ at $77 \mathrm{~K}$ and $\mathrm{CO} 2$ at 298 \\ K. Subsequently, the adsorption of ethanol was carried out and complemented by \\ adsorption of benzene and cyclohexane. The isotherm analysis included application of \\ the $\alpha \mathrm{s}$ method using ethanol reference data obtained here by also studying non-porous \\ carbon blacks. The work confirmed that ethanol is an experimentally convenient \\ adsorptive to use and leads to results in overall agreement with those obtained using \\ other probe molecules. Of particular interest was the observation that ethanol can gain \\ access to the whole microporosity even in the case of samples containing constricted \\ micropore entrances. It was also possible to show that certain furnace carbon blacks \\ contain intrinsic microporosity which is more difficult to unambiguously detect by \\ adsorption of $\mathrm{N} 2$ at $77 \mathrm{~K}$. On the other hand, the results also suggested that the exact \\ shape of the ethanol adsorption isotherm on a nonporous surface is more sensitive to the \\ nature of the surface than has previously been found with other adsorptives.
}

